\title{
Destructive fires are not just Indonesia's problem
}

\section{Logging, urban expansion and lawlessness fan the flames throughout Borneo.}

Sir - Your News Feature "Borneo is burning" (Nature 432, 144-146; 2004) links the mismanagement of peat swamp forests in Central Kalimantan to the appallingly destructive fires that leave the region blanketed in haze and release massive amounts of carbon dioxide whenever there is a substantial drought.

This informative account of the environmental problems associated with Suharto's Mega Rice Project, and recent attempts to rectify them, unfortunately reinforces a misperception that these fires are largely an Indonesian problem, and thus that their ultimate causes lie in the particulars of Indonesian politics.

During the 1997-1998 El Niño event described in the News Feature, drought and fires were widespread in the Malaysian states of Sarawak and Sabah and the independent state of Brunei Darussalam, as well as in Kalimantan. Also, fires were not restricted to peat swamps, as the Indonesian experience suggests, but occurred in agricultural areas, logged forest and even primary rainforest - although peat fires tend to burn for longer and release much larger amounts of smoke and carbon dioxide.

As someone who witnessed these fires and experienced the debilitating effects of the resulting haze, the focus on Indonesia has always disappointed me. If the problem of burning in Borneo and elsewhere in southeast Asia is to be properly addressed, governments and donors in the region must first recognize the widespread nature of the problem.

Indeed, the principal causes are not difficult to identify: they are environmental mismanagement, in particular the development of peat-swamp areas for agriculture (as mentioned in the News Feature), oil-palm plantations or urban expansion; increased access to formerly remote areas, often as a result of logging; and lack of law enforcement because of governments' reluctance or inability to assert authority at a local level.

Until these problems are addressed, fire and haze will continue to plague the region whenever there is a prolonged drought.

The ongoing massive destruction of natural environments and associated carbon dioxide emissions make this a global issue of considerable urgency. Rhett D. Harrison

Smithsonian Tropical Research Institute, Apartado Postal 2072, Balboa Avenue,

Ancon, Republic of Panama

\section{Fighting future fires with fairness}

Sir - In your Editorial "Burning issues" (Nature 432, 131; 2004) you argue that international climate treaties, such as the Kyoto Protocol, should provide incentives to reduce greenhouse-gas emissions from peatlands in Indonesia by including them in an international cap-and-trade system. In the future, one could include peatland restoration in a greenhouse-gas trading system by giving countries such as Indonesia emission targets that explicitly cover those emissions (which is not the case now). However, the difficulty of setting an appropriate target for such variable emissions should not be underestimated.

If there is a risk that Indonesia will again experience peatland-related emissions similar to those released in the 1997 El Niño event (13-40\% of global emissions), it is hard to see how the country could accept a target that would make it accountable for those emissions; reasonably enough, Indonesians consider that they have little control over them.

On the other hand, offering a generous emission target, which would cushion such emission events, runs the risk of inflating the international carbon market with 'tropical hot air' if it turns out that the peatlands do not burn. This would have detrimental consequences for emission-reduction efforts in other parts of the world.

Clearly, these problems affect not only Indonesia but also other countries with large potential changes in their biospheric stock of carbon. Brazil, just like Indonesia, gets a large share of its emissions from deforestation. Annual fluctuations in deforestation-related emissions are as large as the entire Kyoto target for the European Union (see U. M. Persson and C. Azar, Brazil beyond Kyoto, Swedish Environmental Protection Agency, Stockholm, 2004).

In addition to problems in setting appropriate targets, there are huge uncertainties in emission estimates and difficulties in separating human-induced emissions from natural emissions.

One possible way forward is to develop a separate protocol for these highly variable emissions, based on specific policies and measures that encourage better land-use patterns and protection of sensitive ecosystems. This would avoid the uncertainties of targetsetting altogether.

Alternatively, if all carbon emissions were included under the same cap, the target for such variable emissions could be made non-binding, so that carbon credits could only be claimed if emissions fell below a certain level. This would make it politically feasible to negotiate a reasonably tough target, because countries would not be held accountable for emissions exceeding the target. An incentive for peatland restoration and reduced deforestation would be created, while the risk of creating 'tropical hot air' would be diminished.

Finally, although there are difficulties and problems associated with almost all proposals to deal with these problems through international climate negotiations, this should not prevent us from taking action to deal with it on the ground today. Christian Azar, U. Martin Persson Department of Physical Resource Theory, Chalmers University of Technology, S-412 96 Gothenburg, Sweden

\section{Mouse geneticists need European strategy too}

Sir - Your News story "Geneticists prepare for deluge of mutant mice” (Nature 432, 541; 2004) promises mutants "covering every single gene". But the section headed "It's a knockout" notes that many genes will be missed if a simple knockout strategy is exclusively used, owing to embryonic lethal knockouts and compensatory mechanisms.

Clearly, other strategies are needed if the promise to genome researchers is to be kept. The conditional knockout method proposed by a European consortium is intended for use in addition to the simple knockout strategy - not instead of it. Although the conditional knockout method may be more expensive and time-consuming than the simple knockout method, it offers a far more comprehensive picture of gene function, and allows the selection of somatic mutants, which are more closely related to human disease conditions.

It is only through the combination of methods that the News story's promise can become a reality.

Wolfgang Wurst

Institute of Developmental Genetics, GSF Research Centre, Ingolstaeder Landstraße 1, 85764 Munich/Neuherberg, Germany 